\title{
A Implantação das Regras de Segurança de Alimentos como Fator de Melhoria para a Indústria de Ração Animal
}

The Implementation of Food Safety's Rules as an Improvement Factor for the Animal Feed Industry

Ana Carla Ferreira da Luz ${ }^{1}$ (D) orcid.org/0000-0003-3130-1693

Luciana Bazante de Oliveira ${ }^{1}$ orcid.org/0000-0001-9115-896X

${ }^{1}$ Pós-graduação em Gestão da Qualidade e Produtividade, Escola Politécnica de Pernambuco, Pernambuco, Brasil.

E-mail do autor principal: Ana Carla carla.luzfr@gmail.com

\section{Resumo}

O termo segurança de alimentos visa garantir produtos saudáveis, que não causem danos à saúde do consumidor, uma vez que devem ser isentos de perigos. Devido ao crescimento da industrialização e a maior exigência dos consumidores, cresceu a preocupação das empresas com a gestão da qualidade, senso criadas normas com foco em segurança de alimentos, como a NBR ISO 22000:2005. Tal norma tem como um dos pilares o plano APPCC (Análise de Perigos e Pontos Críticos de Controle), que apoia a organização a prevenir a ocorrência dos indesejados perigos. A indústria de alimentação animal também está inserida nesse contexto, especialmente por estar num mercado onde o comprador está cada vez mais preocupado e disposto a comprar o melhor produto para o seu animal. O presente trabalho tem como objetivo demonstrar a importância de um sistema de gestão de alimentos para proporcionar a segurança dos produtos da indústria de alimentação animal, por meio de uma revisão de literatura, visando melhorias contínuas no processo.

Palavras-Chave: Segurança de alimentos; APPCC; Indústria de alimentação animal.

\begin{abstract}
The term food safety aims to ensure healthy products that do not cause harm to the health of the consumer, since they must be free of hazards. Due to the growth of industrialization and the increased requirement of consumers, the concern of companies with quality management has grown, with the creation of standards with a focus on food safety, such as NBR ISO 22000: 2005. This norm has as one of the pillars the HACCP (Hazard Analysis and Critical Control Points) plan, which supports the organization to prevent the occurrence of the unwanted hazards. The animal feed industry is also included in this context, especially because it is in a market where the buyer is increasingly worried and willing to buy the best product for his animal. The present work aims to demonstrate the importance of a food management system to provide the safety of the animal feed industry products through a literature review, aiming at continuous improvements in the process.
\end{abstract}

Key-words: Food safety; HACCP; Animal Feed Industry. 


\section{Introdução}

Cada vez mais, a busca por alimentos com qualidade e seguros torna-se um assunto de grande relevância para os consumidores, por desejarem saber a origem do alimento consumido, bem como a forma como é produzido, e foi nesse contexto que o termo segurança de alimentos passou a ser amplamente discutido [1].

Entende-se por segurança de alimentos a junção de normas que regem todos os processos envolvidos na produção, transporte e armazenamento de alimentos, buscando garantir determinadas características dos produtos, realizando adequações a padrões biológicos e físico-químicos para que esses alimentos estejam aptos ao consumo [2]. Essa junção de normas e diretrizes é seguida mundialmente, de forma que as necessidades sanitárias e comerciais sejam atendidas para satisfazer todo e qualquer cliente em qualquer parte do mundo, garantindo a qualidade e a segurança dos alimentos.

Conforme descrito por Neto [3], o conceito de verificação e neutralização de perigos e riscos é crucial para a garantia de alimentos saudáveis para o consumo, podendo tais perigos serem classificados como os relativos aos organismos, físicos e químicos. Existe uma grande quantidade de produtos no mercado, e por causa da alta competitividade observada no cenário atual, é cada vez mais importante cuidar dos processos, a fim de garantir produtos de qualidade e que atendam às necessidades do consumidor, sem oferecer riscos [4].

Diante desse contexto, as indústrias de alimentação animal procuram não escapar das regras de um mercado cada vez mais competitivo, assim como faz a indústria de alimentação humana [5]. Inquestionavelmente, a empresa deve garantir o produto com elevado padrão de qualidade $\mathrm{e}$ segurança, uma vez que o mesmo afeta o desempenho e/ou saúde do animal. Dessa forma, garantir a qualidade dos processos desde a chegada dos insumos até a expedição do produto final contribui para identificar e solucionar os problemas que possam comprometer a ração [6].

\section{Metodologia}

A metodologia utilizada nesse trabalho foi a pesquisa exploratória-descritiva e qualitativa, com a coleta de dados, desenvolvida a partir de pesquisas em legislações, normas técnicas, artigos científicos, sites e documentos eletrônicos.

Dessa forma, foi feito um referencial teórico sobre o tema, buscando assim um conhecimento amplo sobre a relevância da segurança de alimentos para o aprimoramento da gestão da qualidade e dos resultados nas empresas destinadas a alimentação animal.

\section{Revisão de Literatura}

\subsection{Indústrias de alimentação animal no Brasil}

O setor de alimentação animal no Brasil em 2017 atingiu 72,4 milhões de toneladas, sendo $3,4 \%$ superior ao ano precedente, devido ao efeito da queda dos preços dos insumos, como do milho e da soja, o ganho real da renda, a queda na taxa de juros, entre outros fatores positivos que refletiram na melhora do mercado de alimentação animal [7].

Já para o ano de 2018 a perspectiva de crescimento seria em torno de $3,5 \%$, mas esse ritmo reduziu para $2 \%$, uma vez que a produção no primeiro trimestre foi prejudicada pela elevação nas cotações do milho e depreciação nos preços do frango vivo sem estímulo ao consumo [8].

As fábricas de alimentação animal visam a eficiência de produção, isto é, maior quantidade de ração produzida por hora para obter lucratividade na comercialização. No entanto, as empresas estão cada vez mais atentas à competividade e qualidade, adaptando-se a novas realidades, atendendo às exigências de mercado, leis governamentais e segurança de alimentos, garantindo assim a produção de itens seguros [5].

A produção de rações e concentrados, conforme Biagi [9], é realizada a partir da junção de macro e micro ingredientes, onde o processo consiste basicamente em algumas etapas, sendo elas: recepção e descarga de matéria-prima, armazenamento, pesagem, moagem, mistura, peletização, resfriamento, ensaque e expedição. 


\subsection{Legislações vigentes para as indústrias do setor de alimentação animal no Brasil}

No Brasil, o Ministério da Agricultura Pecuária e Abastecimento (MAPA) é o órgão responsável pela regulamentação e fiscalização do setor de produtos destinados à alimentação animal. Dessa forma, todo estabelecimento que fabrica, fraciona, importa, exporta e comercializa rações, suplementos, premix, núcleos, alimentos para animais de companhia, ingredientes e aditivos para alimentação animal deve ser registrado no MAPA e obedecer as legislações vigentes [10].

A fiscalização realizada por este órgão legal nos estabelecimentos, tem como objetivo garantir adequadas condições higiênico-sanitárias nos processos de fabricação, assim como a conformidade, rastreabilidade e inocuidade dos produtos disponibilizados no mercado [10].

São várias as legislações aplicáveis à indústria de alimentação animal, sendo algumas das mais relevantes para este artigo apresentadas a seguir:

Por determinação do MAPA, o registro dos estabelecimentos e dos produtos destinados à alimentação animal deverá seguir as normas dispostas no Decreto 6.296/07, que regulamenta a Lei 6.198 , de 26 de dezembro de 1974, conhecida como lei de inspeção e fiscalização obrigatória dos produtos destinados à alimentação animal. Já no que se refere as Boas Práticas de Fabricação (BPF) e condições higiênico-sanitárias, os estabelecimentos do ramo devem cumprir o que determina a Instrução Normativa no 04/2007 [10]. Conforme previsto pelo artigo 87, do Decreto 6.296/07, da Instrução Normativa no 42, de 16 de Dezembro de 2010, foram instituídos os critérios e os procedimentos para a fabricação, fracionamento, importação e comercialização, como também os modelos de formulários e as listas de produtos a serem isentos de registro [11].

Além da produção para consumo nacional, toda empresa destinada à alimentação animal, devidamente registrada, que deseja importar ou exportar seus produtos é submetida ao cumprimento de requisitos regulamentados pelo MAPA. Os procedimentos para importação de produtos destinados à alimentação animal estão dispostos na Instrução Normativa no 29 de 14 de Setembro de 2010 [10]. Já as empresas que desejam exportar seus produtos devem atender as normas nacionais e as exigências específicas do país importador, uma vez que a solicitação de certificados de exportação deve ser feita ao serviço responsável pela fiscalização na Superintendência Federal de Agricultura (SFA/MAPA) de jurisdição da empresa [10].

Segundo a Instrução Normativa no 17 de 7 de Abril de 2008, é proibida em todo o território nacional a fabricação, na mesma planta, de produtos destinados à alimentação de ruminantes e não ruminantes [12].

No caso da embalagem, rotulagem e propaganda de produtos destinados à alimentação animal, fica aprovada a Instrução Normativa no 22, de 02 de Junho de 2009, uma vez que informa sobre as informações que obrigatoriamente devem constar nos rótulos dos produtos embalado ou a granel [13].

\subsubsection{Boas Práticas de Fabricação (BPF)}

As BPF são procedimentos higiênicos, sanitários e operacionais aplicados em todo o processo de produção, desde a obtenção das matérias-primas até a distribuição do produto final, com o objetivo de garantir a qualidade, conformidade e segurança dos produtos destinados à alimentação animal. Com o intuito de garantir que os estabelecimentos cumpram os procedimentos necessários para a fabricação de um alimento seguro, o MAPA, conforme adequação da Instrução Normativa no 4, de 23 de Fevereiro de 2007, aprovou o regulamento técnico sobre as condições higiênico-sanitárias e de BPF para estabelecimentos fabricantes de produtos destinados à alimentação animal e o roteiro de inspeção. As normas que estabelecem as BPF para alimentação animal envolvem requisitos fundamentais higiênicosanitários das instalações, equipamentos e utensílios, passando por rigorosas regras de higiênico-sanitários do pessoal e da produção. A legislação destinada à alimentação animal, além de um manual de BPF, estabelece também a obrigatoriedade de elaboração dos procedimentos operacionais padrão relacionados a prevenção e controle de perigos químicos, físicos e biológicos. Todos os procedimentos devem ser aprovados e controlados pela empresa, bem como os funcionários, especialmente os verificadores, devem estar devidamente treinados para execução dos mesmos [14].

http://dx.doi.org/10.25286/repa.v4i1.978 


\subsection{Gestão da Qualidade}

A qualidade pode ser definida como adequação ao uso, conformidade com os requisitos e baixa variabilidade, entre outros conceitos. Talvez a definição mais apropriada à qualidade seria a satisfação e fidelização dos clientes, uma vez que as características de um produto (ou serviço) podem afetar sua capacidade de satisfazer às necessidades dos clientes [15].

Nesse sentido, a evolução histórica da qualidade propôs a quatro etapas ou eras, na qual cada uma apresenta suas peculiaridades, bem como influências no desenvolvimento social e tecnológico, conforme pode ser visualizado na Figura 1.

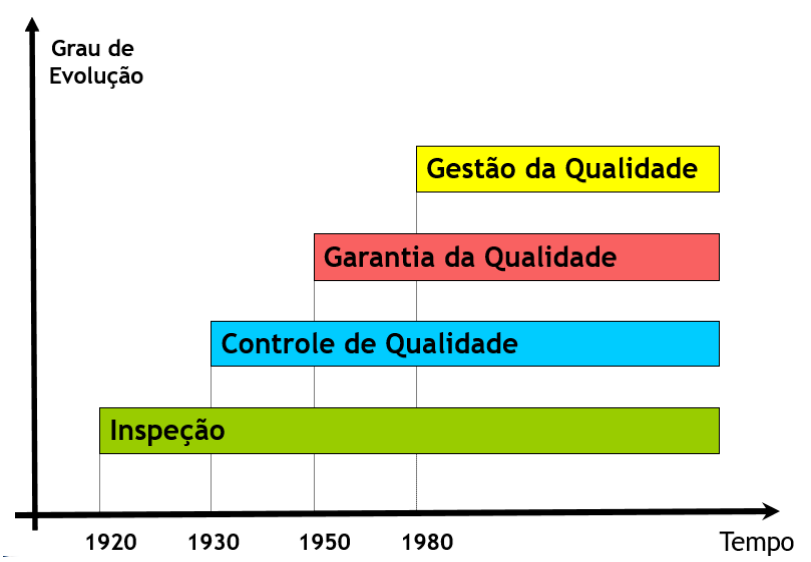

Figura 1: Evolução da qualidade.

Fonte: Autora (2018).

Essa evolução histórica inicia-se com a era da inspeção nos anos 20, uma vez que qualidade costumava ser verificada ao final do processo produtivo, quando cabia ao inspetor a tarefa de identificação ou triagem de produtos que viessem a ter algum tipo de defeito, sendo o seu foco no produto [16].

Com o aumento da escala produtiva, em meados dos anos 30, o estatístico e engenheiro norteamericano Walter A. Shewhart dedicou boa parte de seus esforços em pesquisas que levaram ao surgimento da era do controle de qualidade. Dessa forma, foram aplicadas técnicas de amostragem a fim de eliminar a impraticabilidade e a ineficácia da inspeção [16].

As preocupações com as causas dos defeitos foram marcadas pelo entendimento de novas visões relacionadas à qualidade. Contudo, o foco que era no 157 produto ou serviço, passou a ser um problema nas organizações que, por volta dos anos 50, foi marcada pela valorização do planejamento e coordenação dos processos. $O$ estabelecimento de padrões e técnicas em busca da qualidade foi chamado de etapa da garantia da qualidade [16].

Por fim, a partir dos anos 80 surgiu a etapa da gestão da qualidade, quando a qualidade passou a priorizar o valor dos clientes e a sua satisfação como fator de preservação e ampliação da participação da empresa no mercado [16].

A gestão da qualidade consiste no conjunto de ações a fim de obter características do produto ou serviço que satisfazem as necessidades e expectativas do cliente interno ou externo, uma vez que é uma abordagem para a organização, seja ela micro, média ou de grande porte, que busca a melhoria contínua de todos os seus processos, produtos e serviços [16].

Garantir a qualidade dos produtos/serviços e assegurar a satisfação dos clientes torna-se uma tarefa complexa, diante do constante desafio por melhores resultados, o que demanda a implantação de um sistema de gestão da qualidade nas empresas para facilitar o percurso [16]. Quando se fala em sistema de gestão da qualidade, o controle de processo passa a ser fundamental para que os produtos cheguem aos clientes internos e externos e atendam a sua expectativa [15].

Conforme Silva et al. [17], a partir da etapa da gestão da qualidade, a implantação dos sistemas de gestão da qualidade foi se intensificando. Ainda de acordo com os mesmos autores, a gestão da qualidade deve ser inserida em seu conceito como uma nova maneira de ver as relações entre as pessoas, no qual o benefício comum é superior ao de uma das partes.

\subsection{Ferramentas da Qualidade}

Algumas ferramentas de gestão foram criadas para facilitar a aplicação prática dos conceitos de qualidade total. Dessa forma, após análise dos dados do processo e/ou problemas, os programas e ferramentas da qualidade passaram a exercer um importante papel, visto que sentiu-se a necessidade de gerar ações para corrigir eventuais desvios. Em virtude disso, elas representam importantes 
instrumentos para que os sistemas de gestão da qualidade atinjam máxima eficiência e eficácia [15].

Com o aumento do grau de dificuldade em solucionar problemas, as ferramentas da qualidade entram em cena para otimizar as habilidades e competências da organização, disponibilizando métodos de coleta de dados e técnicas, que iniciam no processo produtivo para a identificação de possíveis causas e descoberta de soluções para os problemas [16].

As ferramentas da qualidade passam a ser de grande utilidade no momento em que as pessoas que compõem a organização começam a dominar e praticar o ciclo PDCA (do inglês: Plan-Do-Check-Act). Entre as ferramentas utilizadas no estudo, pode-se citar: Diagrama de Causa e Efeito (Ishikawa), Estratificação, Gráfico de Pareto, $5 \mathrm{~W} 2 \mathrm{H}$ e Folha de verificação [16].

O ciclo PDCA é um método utilizado para tomada de decisões, visando garantir o alcance das metas atribuídas aos produtos dos sistemas empresariais. Este ciclo foi idealizado por Shewhart, sendo aprimorado posteriormente por Deming que o aplicou efetivamente e divulgou, por isso também é conhecido como Ciclo de Shewhart ou, mais comumente, Ciclo de Deming [16].

Segundo Daniel e Murback [16] o ciclo se divide em quatro fases que devem ser repetidas continuamente. A Figura 2 apresenta alguns detalhes sobre as fases do ciclo PDCA.

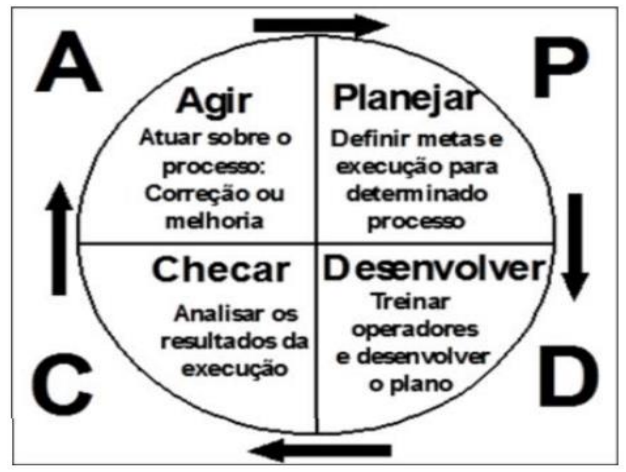

Figura 2: Ciclo PDCA.

Fonte: Daniel e Murback (2014).

A primeira das etapas é o P (Plan/Planejar) nesta fase envolve o levantamento da análise de causa e efeito e análise de dados para que se estabeleçam objetivos, metas, missão, valores, procedimentos e processos necessários para alcançar os resultados estabelecidos; a segunda etapa é o D 158
(Do/Fazer) - é nesse ponto que a empresa irá executar o plano traçado da fase anterior, onde as metas são colocadas em prática; a terceira etapa é o C (Check/Verificar) - nesta etapa são realizados os monitoramentos ou avaliações dos procedimentos para verificar se eles estão sendo desenvolvidos conforme a meta planejada; e a quarta etapa é o $\mathrm{A}$ (Act/Ação) - nesta fase, são executadas as ações para promover a melhoria contínua dos processos, ou seja, as correções necessárias que foram identificadas durante a etapa de verificação. Ao final dessa fase, volta-se a primeira fase, iniciando novamente o ciclo, permitindo que se faça 0 processo de melhoria continua [16].

Todas essas ferramentas têm características próprias que, em conjunto ou individualmente, fornecem métodos e técnicas para as ações da gestão da qualidade [16].

\subsection{Segurança de Alimentos}

O termo representa a segurança de que o consumo de um determinado alimento não causará dano a um consumidor, quando preparado ou consumido de acordo com seu uso intencional. Ele passou a ser utilizado a partir da Primeira Guerra Mundial, na Europa. No período, o conceito estava totalmente voltado a preocupações ligadas ao conceito de segurança nacional e com a capacidade de cada país produzir sua própria alimentação para satisfazer as necessidades alimentares de sua população. Foi somente após a Segunda Guerra Mundial que o conceito de segurança de alimentos ganhou força, particularmente em 1945, com a fundação da Organização das Nações Unidas (ONU). No final da década 1980 e início dos anos 1990, houve a necessidade de tornar estável o conceito de segurança de alimentos, incorporando noções como: alimento seguro (sem apresentar contaminação biológica ou química), qualidade do alimento (biológicas, sanitárias e tecnológicas) e opções culturais [18].

Os sistemas de gestão da segurança de alimentos devem controlar $o$ processo de produção $e$ basearem-se em princípios e conceitos preventivos, juntamente com os programas de pré-requisitos necessários para a implantação dos mesmos. Por meio da utilização de sistemas de gestão da segurança de alimentos pretende-se aplicar medidas de controle eficiente, através da identificação de

http://dx.doi.org/10.25286/repa.v4i1.978 
etapas onde é possível controlar os perigos para a saúde dos consumidores [19].

Os programas de gestão de segurança de alimentos foram desenvolvidos para auxiliar na tarefa de diminuir a frequência ou até mesmo eliminar as contaminações alimentares [19].

\subsection{Normas ISO}

Devido ao crescimento da industrialização e a necessidade de verificação de processos, houve aumento da preocupação com a questão da qualidade, fazendo com que as normas passassem a ser vigentes, de forma a convergir para uma mesma diretriz. Ao observarem o novo método produtivo, passaram a se preocupar com a forma de controle e de cumprimento de padrão, já que parte das atividades era realizada externamente. Dessa forma, criou-se o órgão normalizador ISO, em português significa Organização Internacional de Padronização, responsável pela emissão e verificação das normas e padrões de aceitação mundial, definidas por consenso dos países membros. O organismo atua em campos muito amplos, gerenciando a normalização e padronização de diversas áreas. No Brasil, ele é representado pela Associação Brasileira de Normas Técnicas - ABNT [20].

Com o objetivo de padronizar métodos e procedimentos relacionados à garantia da qualidade na gestão de processos, foi lançada em 1987 a primeira versão da norma referente a sistemas de gestão de qualidade, regida pela série de normas ISO 9000. As empresas puderam, então, implantar e certificar as suas rotinas com base nessa norma. A certificação dos sistemas de gestão atesta publicamente a conformidade do modelo de gestão de fabricantes e induz à busca por melhoria contínua da qualidade, apresentando como indicador para os consumidores de um determinado produto, processo ou serviço que está em conformidade com os padrões mínimos de qualidade. É realizada por uma organização independente, acreditada para executar essa modalidade de avaliação da conformidade [19].

As normas ISO são de grande importância para a área de qualidade e segurança de alimentos, apesar de não serem as únicas no mercado regidas principalmente pela norma ISO 22000 [21]. Ela é fundamentada em elementos-chaves, geralmente reconhecidos para garantir a segurança ao longo da cadeia até o consumo final, conforme pode ser visualizado na Figura 3.

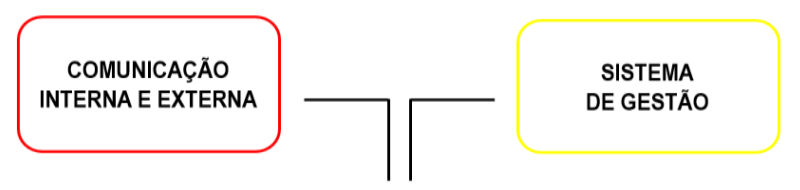

FUNDAMENTOS

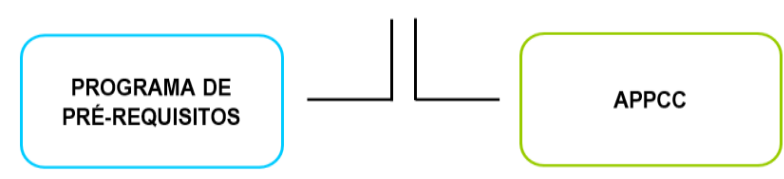

Figura 3: Fundamentos da ISO 22000.

Fonte: Autora (2018).

\subsubsection{A norma ISO 22000}

Com a necessidade de garantir a segurança de alimentos, o organismo ISO desenvolveu uma norma para certificação de um sistema de gestão de segurança de alimentos, pertinente a todas as organizações da cadeia alimentar. Desta forma, em setembro de 2005 foi publicada em âmbito internacional a norma ISO 22000 - Food safety management systems - Requeriments for any organization in the food chain, sendo que em junho de 2006 foi lançada sua tradução oficial em português, denominada NBR ISO 22000:2006 Sistemas de Gestão da Segurança de Alimentos Requisitos para qualquer organização da cadeia produtiva de alimentos [21].

A NBR ISO 22000 foi alinhada aos padrões da NBR ISO 9001 - Requisitos para um sistema de gestão da qualidade, com o objetivo de aumentar a compatibilidade entre elas e possibilitar a sua aplicação em conjunto nas organizações que têm interesse em implementar sistemas que consistentemente garantem produtos seguros [21].

Segundo a ABNT [22] para a implementação da ISO 22000, a organização deve seguir os requisitos que estão descritos nesta Norma, a fim de garantir uma eficiência da segurança de alimentos. Os requisitos estão descritos a seguir:

- Sistema de gestão da segurança de alimentos: Requisitos gerais e requisitos de documentação;

- Responsabilidade da direção: comprometimento da direção; Política de segurança de alimentos; Planejamento do sistema de gestão da segurança de alimentos; 
Responsabilidade e autoridade; Coordenador da equipe de segurança de alimentos; Comunicação (externa e interna); Prontidão e resposta a emergências; Análise crítica pela direção;

- Gestão de recursos: Provisão de recursos; Recursos humanos; Infraestrutura; Ambiente de trabalho;

- Planejamento e realização de produtos seguros: Generalidades; Programa de prérequisitos (PPR); Etapas preliminares para permitir a análise de perigos; Análise de perigos; Estabelecimento dos programas de Pré-requisitos operacionais (PPR); Estabelecimento do plano APPCC; Atualização de informações preliminares e documentos especificando os PPR e o plano APPCC; Planejamento da verificação; Sistema de rastreabilidade; Controle de nãoconformidades;

- Validação, verificação e melhoria do sistema de gestão da segurança dos alimentos: Generalidades; Validação das combinações de medidas de controle; Controle de monitoramento e medição; Verificação do sistema de gestão da segurança dos alimentos; Melhoria.

A norma ISO 22000 apresenta requisitos para implantação de um sistema de gestão da segurança de alimentos e este, quando implementado, apresenta diversos benefícios para a organização, como por exemplo [23]:

- Oportunidade de melhoria e otimização do sistema e processos de gestão;

- Melhoria na realização do produto;

- Melhoria na comunicação;

- Melhoria na eficiência de resultados;

- Cumprimentos dos requisitos estatuários, regulamentares e de clientes;

- Motivação e envolvimento dos colaboradores;

- Imagem e prestígio.

A norma ISO 22000 é passível de auditorias, integrando os princípios do APPCC e as etapas de aplicação desenvolvidas pelo Codex Alimentarius. Visto que a mesma combina o plano APPCC com os Programas de Pré-Requisitos (PPR), a sua intenção é harmonizar os requisitos de gestão da segurança de alimentos na cadeia produtiva [22].

\subsubsection{APPCC}

A sigla refere-se à Análise de Perigos e Pontos Críticos de Controle. Ela é referência dentro do sistema de gestão de segurança de alimentos, buscando a análise de potenciais riscos à qualidade e segurança dos produtos para o consumidor final, buscando mitigar tais riscos, reduzindo-os ao mínimo aceitável e/ou eliminando-os, em prol de proporcionar competitividade entre as organizações. Isso ocorre pela grande complexidade em garantir a qualidade e segurança de processos e produtos. A grande suscetibilidade de contaminação faz o APPCC atividade crucial para 0 desempenho das organizações [24].

A implementação do APPCC data de 1959, onde os alimentos que seriam enviados ao espaço, e por lá utilizados, demandavam cuidados especiais por conta da atmosfera. Isso incluía desde a possível suspensão de partículas até a contaminação por microrganismos patogênicos presentes nos alimentos que poderiam se comportar de formas diferentes dependendo da sua localização [25].

A continuidade de estudos ocorreu a partir da década de 70, quando foi publicado o primeiro documento sobre APPCC e encabeçado por estudiosos da Academia Nacional de Ciências dos Estado Unidos (1985), Comissão Internacional de Especificações Microbiológicas para Alimentos (1988), sendo integrado ao Codex Alimentarius em 1993 [15].

Criado em 1963, o Codex Alimentarius iniciou suas atividades em uma conferência organizada pela Food and Agriculture Organization (Organização para comida e agricultura) - FAO e Organização Mundial de Saúde - OMS, com o objetivo de estabelecer medidas sanitárias de inocuidade e segurança de alimentos. Seus principais objetivos são proteger a saúde dos consumidores e garantir práticas leais de comércio entre os países [26]. Na década de 70, o Brasil tornou-se membro deste programa, porém só em 1980 que conseguiu uma articulação mais representativa do setor alimentício, com a criação do Comitê do Codex Alimentarius do Brasil (CCAB). O $C C A B$ é composto por 13 membros de órgãos do governo, das indústrias e de órgãos de defesa do consumidor, como por exemplo das leis estabelecidas pela Agência Nacional de Vigilância Sanitária (ANVISA) e MAPA [26]. 


\section{A Implantação das Regras de Segurança de Alimentos como Fator de Melhoria para a Indústria}

de Ração Animal

A partir de 1993, a sistemática passou a ser adotada em indústrias alimentícias da época, sobretudo em potências mundiais, sendo posteriormente estendida às empresas de produtos de origem animal, cujo pré-requisito está vinculado às BPF [27].

\subsubsection{Etapas de Estruturação do APPCC}

Conforme a ABNT NBR ISO 22000:2006 [22], a organização deve cumprir uma sequência lógica de 12 etapas para implementação do APPCC, a começar pela execução das etapas preliminares para permitir a análise de perigos, conforme a seguir:

- Definição da equipe de segurança de alimentos: esta etapa inicial serve para realizar a estruturação da equipe que será responsável pelas práticas de controle e fiscalização. Ela reúne profissionais com conhecimentos específicos em Engenharia, Produção e Qualidade para nortear as atuações nessas áreas a fim de criar um controle fino de verificação da segurança, obedecendo caráter funcional e não hierárquico. Ela visa definir os campos de verificação, apreciar as dificuldades e limites, garantir o cumprimento da norma, proceder informações à gerência e estabelecer planos de ação;

- Características dos produtos: esta etapa visa criar uma auditoria prévia do produto, realizando o levantamento de todas as variáveis a serem consideradas no sistema, buscando o estudo e a descrição dos produtos e das matérias primas utilizadas, ingredientes e outros insumos auxiliares;

- Descrição das etapas do processo e medidas de controle: esta etapa é responsável por auditar o produto e o processo utilizado para obtenção do produto final, identificando e avaliando o papel dos elementos e fatores auxiliares do processo ligados ao ambiente. Nesse momento é realizada a dissociação de etapas complementares de etapas principais, com a finalidade de não sobrecarregar os sistemas. A partir dela, passa-se a ser facilitada a implementação dos níveis seguintes, por meio da criação do fluxograma dos processos produtivos;
- Avaliação do uso pretendido: realiza a complementação de informações previamente fornecidas, buscando calcular a durabilidade padrão do produto em condições normais de armazenamento e uso;

- Descrição dos fluxogramas: devem ser claros, precisos e suficientemente detalhados. 0 mesmo deve incluir: sequência e interação de todas as etapas do processo; quaisquer processos externos e trabalhos subcontratados; onde os insumos e produtos intermediários entram no fluxo; onde o retrabalho e recirculação ocorrem; momento onde os produtos finais, produtos intermediários, subprodutos e resíduos são liberados ou removidos. Além do mais, devese verificar a precisão dos fluxogramas através de uma checagem in loco, a fim de assegurar ao mesmo tempo a viabilidade do fluxo de processos e a repetitibilidade das informações encaminhadas e mantê-los como registro.

Após a execução dos passos preliminares, faz-se necessário aplicar os sete princípios básicos que correspondem a uma forma prática de identificar e controlar os perigos significativos. São eles:

- Conduzir uma análise de perigos: este primeiro princípio visa identificar os potenciais perigos que possam ocorrer durante as etapas. Nela ocorre todo o mapeamento de matéria prima, procedimentos, práticas e outras circunstâncias relativas à produção;

- Determinar os pontos críticos de controle (PCC): esta etapa corresponde à verificação de etapas operacionais que podem se tornar críticos à produção. Sua idealização consiste em eliminar riscos e perigos, ou minimizar sua probabilidade de afetar o sistema, através da árvore decisória;

- Estabelecer limites críticos: em cada ponto de identificação de pontos críticos, a equipe implementadora do APPCC deverá definir valores como metas a serem atingidas para manter o funcionamento dos sistemas em níveis aceitáveis. Essas tolerâncias são relativas e variam de material a material e de a processo, podendo ser químicos, microbiológicos, ou sensoriais quando relacionados aos processos especificamente;

- Estabelecer um sistema de monitoramento: nessa fase de implantação, a idealização de 
monitoramento e melhoria do sistema vem à tona. Neste ponto é necessário estabelecer métodos e dispositivos de controle, por meio de observações e/ou testes, podendo assim garantir a efetividade dos indicadores e dos componentes observados, sejam eles controlados ou apenas observados, em casos de grandezas adimensionais;

- Estabelecer ações corretivas: quando houver falha em todas as etapas que visam antecipar e mitigar os riscos, há a necessidade de tratar as falhas que não foram possíveis de se constatar ou reduzir a níveis baixos. Deve haver um dimensionamento para cada ponto crítico observado, com suas respectivas tratativas, criando uma forma de check-list de verificação e tratativa de riscos;

- Estabelecer procedimentos de verificação: consiste em verificar todos os outros passos tomados anteriormente e criar uma forma de atuação, padronizando os processos e realizando a elaboração de indicadores que servirão para ilustrar toda a atuação do programa. Essa verificação possibilita aos responsáveis validar o sistema empregado e determinar sua propensão ao funcionamento ou à falha, podendo assim exigir as necessidades de segurança e qualidade requeridas.

- Estabelecer documentação: para que haja divulgação de informações e para que observações passadas sirvam de base para avaliações de problemas futuros, fica sendo necessária a documentação de todas as ocorrências observadas. No modelo documental, podem ser empregados os procedimentos, voltados aos operadores e trabalhadores de controle de processos, e as avaliações observadas, que servem para a constatação e imposição de melhorias aos processos.

Assis [19] afirma que caberá sempre à equipe destinada à criação do APPCC realizar a organização de itens a serem inspecionados e verificados, como as modalidades, períodos, atividades, procedimentos, e métodos, podendo assim formalizar as instruções de atuação e padronizar um modelo para toda a organização. Tudo deve ser devidamente documentado para que sirva de base para atuações futura, onde cada verificação realizada deverá dar origem a um relatório descritivo das atividades e constatações.

\section{Discussões e Resultados}

Os cenários atuais de competitividade entre as organizações vêm evoluindo cada vez mais, exigindo das empresas do ramo alimentar a buscarem ferramentas adicionais e implementarem sistemas de gestão da qualidade e segurança dos alimentos eficazes e eficientes. No Brasil, por exemplo, às BPF e o APPCC são demandados por órgãos de fiscalização nas empresas de alimentos, atestando a sua eficácia para a fabricação de itens seguros.

Dessa forma, a melhoria contínua é um processo que garante um diferencial competitivo e, deste modo, a implementação do plano APPCC se torna fundamental como impulsionador deste diferencial, uma vez que tem em sua estrutura ações de investigação da causa dos possíveis desvios.

A exemplo da indústria de alimento para consumo humano, a indústria de alimentação animal também se beneficia com a implantação das regras de segurança de alimentos. Não apenas por pressão legal, mas a implantação de tais requisitos traz melhorias à imagem da empresa, pelo entendimento da fabricação de produtos seguros, bem como traz melhoria aos seus resultados.

A ISO 22000 se torna fundamental por apresentar comprometimento em qualquer estágio da cadeia alimentar, uma vez que impede que os perigos sejam introduzidos no processo da cadeia produtiva. Sendo assim, torna-se importante o uso constante de novas técnicas nas operações de pós-colheita de grãos e de industrialização de rações, para manter a qualidade na sequência da cadeia produtiva.

Segundo matéria do site G1 [28], o Brasil é o terceiro mercado mundial de animais de estimação e os gastos com tais seres vem crescendo exponencialmente. Então além de considerar a necessidade moral de proporcionar saúde e bem estar a qualquer ser vivo, a segurança de alimentos aplicada à de ração animal, seja ele de estimação ou usado para fins comerciais, é realmente um fator preponderante na detecção e prevenção de problemas, o que proporciona alguns benefícios:

- Torna confiável a imagem das empresas que implantam as suas demandas;

- Direciona os clientes para comprar seus produtos para garantir a saúde de seus animais e;

http: / / dx.doi.org/10.25286/repa.v4i1.978 
- Previne erros, retrabalhos e recolhimentos;

- Melhorar os resultados das empresas;

- $\quad$ Entre outros.

\section{Conclusão}

O presente artigo proporcionou o estudo da importância da implantação de um sistema de segurança de alimentos para as indústrias de alimentação animal, uma vez que assegura que 0 produto foi fabricado de acordo com a legislação vigente, estabelecida pelo órgão regulador (MAPA), objetivando a produção de um alimento seguro e buscando atender as exigências de um mercado consumidor cada vez mais rigoroso.

O APPCC é uma ferramenta da qualidade que atua na detecção preventiva de potenciais problemas (no levantamento de perigos e monitorização) e solução de problemas reais (definição de ações corretivas no princípio 5).

Sendo assim, se tratando das indústrias de alimentação animal, a qualidade intrínseca da ração divide-se em duas dimensões, qualidade nutricional e sanitária. A qualidade nutricional se presta ao atendimento dos níveis nutricionais de cada fase de vida do animal. Os níveis nutricionais são alcançados através da dosagem e pesagem adequada dos ingredientes individuais, e posterior mistura para homogeneização dos ingredientes.

Já para a ração ter qualidade do ponto de vista da segurança sanitária, deve ser isenta de contaminação, uma vez que qualquer problema não controlado pode afetar, não somente a saúde do animal, mas também de forma indireta a saúde humana no consumo de produtos de origem animal.

\section{Referências}

[1] VIEIRA, V. A. Consumerismo: uma revisão nas áreas de influência do comportamento do consumidor. (Dissertação) Curso de Administração de Empresas e Comércio Exterior da Universidade Paranaense (UNIPAR), Campus Francisco Beltrão, Paraná. 2004.

[2] PASCOAL, G. B. et al. Segurança Alimentar e Nutricional. São Paulo: Editora Rubio, 2015.
[3] NETO, R. G. Livro - Segurança Alimentar: Da Produção Agrária à Proteção do Consumidor. São Paulo: Editora Saraiva, 2013.

[4] FORSYTHE, S. J. Microbiologia da Segurança dos Alimentos. 2 ed. São Paulo: Editora Artmed, 2013.

[5] PENA. H. C. Fabricação de Rações e Suplementos para Animais; Ed Aprenda Fácil; 2008; Páginas utilizadas: $16,17,18,28,33-44 ; 46,52$, 90, 91.

[6] BELAVER, C. A qualidade dos ingredientes e dos itens importantes na produção de rações. Revista A Lavoura, no 642, p.13-15. Rio de Janeiro, 2002.

[7] FORMIGONI, I. Os resultados de 2017 do mercado de alimentação animal revelam crescimento e as perspectivas seguem otimistas para 2018. 2017. Disponível em: <http://www.farmnews.com.br/mercado/alimenta cao-animal-2/>. Acesso em: 06 de Junho de 2018.

[8] ZANI, Ariovaldo. Sindirações. Disponível em: $<$ http://sindiracoes.org.br/industrias-de-racoes-jareduziram-de-35-para-2/ $>$. Acesso em: 06 de Junho de 2018.

[9] BIAGI, J. D. Implicações da granulometria de ingredientes na qualidade de pellets e na economia da produção de rações. In: Simpósio sobre Granulometria de Ingredientes e Rações para Aves e Suínos. Anais. Concórdia: EMBRAPA CNPSA, 1998. p.57-70.

[10] MAPA, Ministério da Agricultura Pecuária e Abastecimento. Disponível em: < http://www.agricultura.gov.br/>. Acesso em: $30 \mathrm{de}$ Abril de 2018.

[11] BRASIL. Ministério da Agricultura Pecuária e Abastecimento (MAPA). Instrução Normativa no 42, de 16 de Dezembro de 2010.

[12] BRASIL. Ministério da Agricultura Pecuária e Abastecimento (MAPA). Instrução Normativa $n^{\circ}$ 17, de 07 de Abril de 2008. 
[13] BRASIL, Ministério da Agricultura Pecuária e Abastecimento (MAPA). Instrução normativa $n^{\circ}$ 22, de 02 de Junho de 2009.

[14] BRASIL, Ministério da Agricultura, Pecuária e Abastecimento (MAPA). Instrução Normativa n04, de 23 de fevereiro de 2007.

[15] COLLETO, D. Gerenciamento da segurança dos alimentos e da qualidade na indústria de alimentos. 2012. 46 f. Trabalho de Conclusão de Curso (Graduação) - Curso de Engenharia de Alimentos. Universidade Federal do Rio Grande do Sul, Porto Alegre, 2012.

[16] DANIEL, É. A.; MURBACK, F. G. R. Levantamento Bibliográfico do Uso das Ferramentas da Qualidade. Gestão\&conhecimento: Revista do Curso de Administração, Poço de Caldas, n. 8, p.1-43, 29 dez. 2014.

[17] SILVA, L. C. S.; KOVALESKI, J. L.; GAIA. S. Gestão da qualidade do produto no processo de produção industrial: um estudo de caso em uma indústria de bebidas. Revista de Engenharia e Tecnologia, Ponta Grossa, v.4, n.1, p.55-67, abr. 2012.

[18] DIAS, J. D. N. Viabilidade da Validação da Escala de Aferição de Insegurança Alimentar em Guiné-Bissau. 2011. 78 f. Monografia (Especialização) - Curso de Saúde Pública, Centro de Pesquisa Ageu Magalhães, Fundação Oswaldo Cruz, Recife, 2011.

[19] CAPIOTTO, G. M.; LOURENZANI, W. L.; Sistema de Gestão de Qualidade na Indústria de Alimentos: Caracterização da Norma ABNT NBR ISO 22.000:2006. In: Congresso SOBER Sociedade Brasileira de Economia, Administração e Sociologia Rural, 48, 2010, São Paulo. Anais: Resr. p. $01-20$.

[20] ASSIS, L. Alimentos Seguros - Ferramentas para gestão e controle da produção e distribuição. $2^{\circ}$ ed. São Paulo: SENAC, 2014.
[21] SALVARO, F. T. Análises de Perigos e Pontos Críticos de Controle (APPCC), em uma Indústria de Beneficiamento de Arroz. 2014. 109 f. TCC (Graduação) - Curso de Engenharia Ambiental, Universidade do Extremo Sul Catarinense, Criciúma, 2014.

[22] ASSOCIAÇÃO BRASILEIRA DE NORMAS TÉCNICAS. NBR ISO 22000:2006: Sistemas de gestão da segurança de alimentos - Requisitos para qualquer organização na cadeia produtiva de alimentos. Rio de Janeiro, 2006. 35 p.

[23] DIAS, S. I. P. Implementação da Norma ISO 22000:2005 numa Indústria de Transformação de Frutos Secos. 2010. 106 f. Dissertação (Mestrado) - Curso de Tecnologia e Segurança Alimentar, Faculdade de Ciências e Tecnologia da Universidade Nova de Lisboa, Lisboa, 2010.

[24] MELO, M. T; NETO, A. M. A. Brasil: Potência alimentar - Segurança dos Alimentos de Origem Animal. Porto Alegre: Sociedade Nacional de Agricultura, 2014.

[25] BERTHIER, F. M. Ferramentas de gestão da segurança de alimentos: APPCC e ISO 22000 (uma revisão). 2007. 37 f. Monografia (Especialização em Tecnologia de Alimentos) - Centro de Excelência em Turismo, Universidade de Brasília, Brasília, 2007.

[26] ANVISA. Agência Nacional de Vigilância Sanitária. Disponível em: <http://portal.anvisa.gov.br/servicos/notivisa/frml ogin.asp>. Acesso em: 05 de Junho de 2018.

[27] FURTINI, L. L. R.; ABREU, L. R. Comunicação e utilização de APPCC na indústria de alimentos, Lavras, 2006, Ciência agrotec. P. 358363.

[28] G1. Disponível em: <https://g1.globo.com/sp/bauru-marilia/especialpublicitario/amigos-pet/noticia/brasil-e-o-terceiromaior-mercado-do-mundo-em-faturamento-nosetor-pet.ghtml>. Acesso em: 18 de Junho de 2018.

http://dx.doi.org/10.25286/repa.v4i1.978 